\title{
Gratuidad y subsidiariedad: una mirada política a la fraternidad católica
}

\author{
Gratuity and subsidiarity: a political view of Catholic fraternity
}

\author{
DANIEL GAMPER*
}

\begin{abstract}
Resumen: El concepto de fraternidad en la Doctrina Social de la Iglesia entiende la naturaleza humana en términos relacionales. Los deberes fraternos son consustanciales a la naturaleza humana y por tanto el conflicto entre libertad e igualdad queda atenuado. En el contexto de la economía globalizada, la fraternidad, vinculada al principio de gratuidad y a la lógica del don, se propone como vía para lograr una humanización de una economía que amenaza con independizarse del control político. En términos católicos, esta fraternidad se acoge al principio de subsidiariedad. Frente a las concepciones contractualistas de la fraternidad que parten del conflicto, la fraternidad católica mantiene una antropología relacional que naturaliza la motivación para el ejercicio de los deberes fraternos.

Palabras clave: fraternidad, justicia, subsidiariedad, institucionalismo, motivación.
\end{abstract}

\begin{abstract}
The concept of fraternity or brotherhood in the Social Doctrine of the Church arises from a relational concept of humankind. Fraternal duties are inherent to human nature, therefore conflicts between freedom and equality diminish. In the context of the global economy, fraternity, linked to the principle of gratuitousness and the logic of gift, is proposed as a way to achieve a more human economy. In Catholic terms, fraternity requires the principle of subsidiarity. In contradistinction to contractarian conceptions of fraternity that presuppose an initial conflict, Catholic fraternity presupposes a relational anthropology that naturalizes the motivation to exercise fraternal duties.
\end{abstract}

Keywords: fraternity, justice, subsidiarity, institutionalism, motivation.

\section{Planteamiento del problema}

A diferencia de la libertad y la igualdad, la fraternidad no ha encontrado una traducción institucional precisa. Libertad e igualdad se han concretado en derechos individuales y colectivos, es decir, los ciudadanos deben poder ejercer las libertades en condiciones de igualdad y en el caso de que encuentren obstáculos o impedimentos pueden elevar sus reivindicaciones y quejas a las instituciones del Estado. ¿Cómo sería un derecho a la fraternidad? ¿Qué la diferencia de la igualdad? ¿No se trata, más bien, de un sentimiento que puede darse entre ciudadanos pero que no se puede imponer legalmente?

Recibido: 07/06/2018. Aceptado: 02/07/2018.

* Universitat Atutònoma de Barcelona, Profesor de filosofía política y moral. daniel.gamper@uab.cat. Ha publicado recientemente Laicidad europea. Apuntes de filosofía política postsecular (Edicions Bellaterra). 
Estas y otras preguntas han alimentado el debate reciente sobre la fraternidad entre los partidarios de una institucionalización político-jurídica de los vínculos fraternos y los que consideran que se trata de un sentimiento, una metáfora, una exhortación o una idea pre-política de la que las instituciones pueden beber pero que no admite una concreción institucional.

En las siguientes páginas, se propone una interpretación de la fraternidad en el contexto de la tradición católica, en concreto desde la Doctrina Social de la Iglesia (DSI). Al inclinarnos por esta clave de lectura se diría que ya hemos decidido responder negativamente a la pregunta sobre la institucionalización de los vínculos fraternos. A primera vista, la DSI trata de las obligaciones morales y sociales de los fieles, pero no propone soluciones políticas ni arreglos institucionales, fiando la fraternidad a la sociedad civil. Para la Iglesia católica, el deber de fraternidad se acoge al principio de subsidiariedad: corresponde a la sociedad civil, a los cuerpos intermedios, realizar acciones fraternas. Concebida así, la fraternidad católica consistiría en las obras de caridad y beneficencia que desde la gratuidad realizan los creyentes.

El otro polo que guía la presente lectura de la fraternidad en la DSI es el de la economía globalizada. A partir del principio de gratuidad que debe orientar la relación fraterna, la DSI, en especial en la encíclica Caritas in veritate de Benedicto XVI, propone formas de relación social que atenúen los efectos perversos de la economía financiera globalizada. De este modo se recoge el hecho de que la fraternidad, al igual que la solidaridad, se caracteriza por "su sustancial irreductibilidad a la lógica del mercado" (Rodotà, 2014, 55). La fraternidad introduce obligaciones morales no contractuales basadas en la lógica del don que no persigue el agradecimiento, que no pone al necesitado en situación de inferioridad, que no se atiene a la simetría y reciprocidad del intercambio contractual (Zamagni, 2009).

\section{Palabras preliminares}

Si contrastamos la filiación cristiana del concepto de fraternidad con su raíz revolucionaria o ilustrada, salta a la vista una diferencia antropológica básica. Las reivindicaciones contemporáneas de la fraternidad por parte de la filosofía política no suelen basarse en una concepción explícita y concreta de la naturaleza humana. Esta ausencia es habitual en un pensamiento que se quiere postmetafísico, antifundacionalista o meramente liberal y que, por tanto, parte de una renuncia razonada a toda afirmación controvertida e indemostrable sobre la esencia de lo humano. En cambio, el pensamiento católico adopta necesaria y desacomplejadamente una cosmovisión concreta en la que lo humano es definido de manera precisa y dogmática. Estos puntos de partida discrepantes hacen casi imposible un trasvase entre ambas esferas del pensamiento a no ser que se dé una tarea específica de traducción cuya carga debería recaer tanto en los secularizados como en los creyentes para que llegara a buen fin.

Sin embargo, si prestamos atención a los rasgos concretos de la fraternidad filosófico-política contemporánea observamos que la reivindicación de un sesgo "político, no metafísico" no es en absoluto indiscutible. Así, el principio de diferencia, que se corresponde con la fraternidad en el sistema de Rawls, está motivado por el autointerés de los individuos (Rawls, 1971)1. Como señalaron en su momento los pensadores comunitaristas, la teoría de la justicia de Rawls antepone

1 Esta afirmación debería ser contrastada con lo enunciado por el propio Rawls en su tesis de 1942 (Rawls, 2009; Habermas, 2010). 
el individuo a sus fines, haciendo de estos el resultado de las decisiones libres y voluntarias de aquellos (Taylor, 1994; Sandel, 2000). Hay, pues, una opción a favor de una antropología individualista que se contrapone a la concepción tomista y aristotélica así como al personalismo que enfatizan la "naturaleza intrínsecamente social del hombre" (Pizzolato, 2012a, 389-391).

El neocontractualismo rawlsiano propone una mediación entre libertad e igualdad, de modo que se presupone ya un conflicto entre ambos principios: las exigencias de la igualdad pueden limitar los deseos de libertad de las personas. Rawls disuelve la contraposición anteponiendo la libertad a la igualdad. De este modo se protege a los ciudadanos de intervenciones que, en aras de la igualdad de oportunidades y de la mejora de condiciones de los más desfavorecidos, limiten su libertad de acción. A esta visión conflictual subyace una antropología de signo individualista, según la cual los individuos no se conciben primariamente como miembros de una comunidad, sino como amasijos de intereses que se protegen de intromisiones externas que les impidan satisfacerlos.

El atractivo y la enorme potencia de la teoría de la justicia de Rawls radica justamente en que, a pesar de mantener una visión eminentemente individualista, introduce medidas correctoras de la desigualdad sin que se vulnere la libre actividad de las personas y sin fiarlo todo a la filantropía, como querría el neoliberalismo anarquista (Nozick, 1974). Con el principio de diferencia, Rawls traduce la fraternidad a procedimiento institucional: la arbitrariedad en el reparto de las dotaciones naturales de las personas, lo que él llama "lotería natural", justifica que los participantes en la situación original opten por una redistribución de la riqueza en beneficio de los más desfavorecidos. Dado que no somos responsables de nuestras circunstancias, vinculamos nuestra suerte a la de los otros. Renunciamos a una parte de nuestra libertad porque cuando decidimos los términos de la cooperación social nos situamos desde el autointerés en el peor de los escenarios posibles (maximin).

Rawls mantiene una mirada individualista y por este motivo debe justificar los deberes recíprocos a través del tortuoso e ingenioso camino del principio de diferencia. En cambio, desde una antropología cristiana no es necesario construir mecanismos que justifiquen los sacrificios personales. Para el cristianismo, la fraternidad es una realidad de hecho, a saber, somos hermanos en Cristo, y por tanto los deberes que de ello se siguen no requieren una justificación ulterior. Si el ser humano es primordialmente un miembro de una comunidad, es decir, si la comunidad es siempre ya y, por tanto, no existe tal cosa como un individuo aislado, entonces no se da un conflicto entre libertad e igualdad pues los deberes de fraternidad se generan en esta comunidad previa.

\section{La fraternidad cristiana según Joseph Ratzinger: teología y globalización}

El concepto de fraternidad desarrollado por Joseph Ratzinger se halla principalmente en dos textos separados por casi cincuenta años. En un breve tratado de 1960, propuso una reconstrucción de la fraternidad cristiana para una correcta interpretación de la fe católica. Este objetivo modesto es superado con creces en la encíclica de 2009, en donde se propone la fraternidad cristiana como modelo a adoptar para una superación de las injusticias y desigualdades en el contexto globalizado. Mientras en el primer texto se trata de un análisis exclusivamente teológico, el segundo sitúa a la fraternidad como piedra de toque de la Doctrina Social de la Iglesia. 
En el libro Die christliche Brüderlichkeit (La fraternidad cristiana) de 1960, Joseph Ratzinger recopila las diversas versiones de la fraternidad en las Escrituras y su posterior adaptación por la teología cristiana. Ratzinger desarrolla su análisis en torno a dos problemáticas: las semejanzas y desemejanzas entre las interpretaciones de la fraternidad cristiana y las filosóficas; y la tensión en el interior de la propia tradición bíblica entre una fraternidad exclusiva y particularista, y una inclusiva y universalista.

A propósito de la fraternidad ilustrada, representada en el tríptico revolucionario, escribe Ratzinger:

"La fraternidad universal es pensada esencialmente desde abajo, a partir de una ascendencia y una naturaleza comunes de todos los humanos. Se refiere a algo que está detrás de la historia, a una naturaleza humana previa a la historia" (Ratzinger, 2006, 32-33).

La igualdad ilustrada sería una restauración de una naturaleza previa que se ha pervertido en desigualdades impuestas arbitrariamente a lo largo de la historia. Ratzinger le objeta a esta "fraternidad excesivamente expandida" que resulta "irrealista y vacía de significado. [...] En efecto, una fraternidad que debe referirse a todos en igual medida no puede referirse seriamente a nadie" (Ratzinger, 2006, 34). Ratzinger sustituye el universalismo ilustrado por la distinción entre dos formas de fraternidad, una hacia el interior del grupo y otra hacia el exterior.

La fraternidad cristiana se explica desde la trascendencia. Surge debido al "empequeñecimiento de las diferencias mundanas ante el encuentro con el único verdaderamente grande, el único verdaderamente Otro: Cristo" (Ratzinger, 2006, 48). Pero, antes de que se dé la universalización del vínculo fraterno, se deben cerrar nudos internos en la forma de una confraternidad, una Bruderschaft que liga a unos pocos: "Para Jesús los hermanos son los que se hallan unidos a él por la aceptación común de la voluntad de Dios. El sometimiento común de la voluntad bajo Dios crea la relación interna de la que aquí se trata. La diferencia con la ideología ilustrada así como con la fraternidad universal de la Stoa es evidente: la fraternidad no se entiende en modo naturalista como un fenómeno originariamente natural, sino que se funda en una decisión espiritual, en el sí a la voluntad de Dios" (Ratzinger, 2006, 52). Existe, en este concepto limitado de fraternidad, una frontera que separa a los creyentes de los que no tienen fe. En Pablo el problema aún no se resuelve, de modo que el concepto de fraternidad "no está en modo alguno completamente universalizado. Todo hombre puede ser cristiano, pero solo el que lo deviene realmente es hermano" (Ratzinger, 2006, 65). Esta concepción limitada de la fraternidad es especialmente relevante para el teólogo alemán: "Solo este uso limitado del concepto de hermano es cristiano; la eliminación de este límite es ilustrada. Solo en esta limitación es en general realizable el concepto de hermano" (Ratzinger, 2006, 113).

Esta limitación interna de los hermanos en Cristo tiene también una vertiente universal. Solo los que comparten la fe son propiamente hermanos, pero la tarea de estos no consiste en recluirse en su comunidad o en la feligresía, sino que hay una proyección hacia el exterior. Ahí radica el aspecto performativo de la fraternidad: "La fraternidad (Brüderlichkeit) cristiana realiza su obligación con la totalidad mediante la misión, el agape y el sufrimiento" 
(Ratzinger, 2006, 126). Son tareas que corresponden a los cristianos, que son los menos, frente a los "otros" hermanos, y que se concretan en el servicio misionario: "id, pues; enseñad a todas las gentes" (Mt 28,19). El agape se manifiesta en el ejemplar comportamiento de los hermanos cristianos que deben "dirigir su amor a todos los que lo necesitan, sin pedir agradecimiento ni respuesta. Cualquiera que necesita su ayuda es, con independencia de sus convicciones, un hermano de Cristo, más aún, una manifestación del Señor mismo" (Ratzinger, 2006, 139-140). El cristiano se comporta, pues, fraternalmente cuando atiende a los necesitados. Por último, al igual que Jesús vino "a servir y a dar su vida en rescate por muchos" (Mc 10,45), el cristiano debe verse como uno de los "pocos" que sufren por los "muchos", por todos. "En su amor y en su sufrimiento sobrepasa todas las fronteras, es verdaderamente "católico"” (Ratzinger, 2006, 142).

Hasta aquí la reconstrucción realizada por Ratzinger a mediados del siglo XX a propósito de cómo debe entenderse la fraternidad en el contexto católico. El énfasis de su interpretación recae en la dificultad de realizar el ideal eminentemente abstracto de la fraternidad secularizada, y por tanto en la importancia de dotar de fuerza motivacional a las acciones fraternas. La comunidad católica unida en torno a la celebración de la eucaristía es el motor propulsor de estas acciones. De este modo logra cumplir las exigencias performativas de la fraternidad, que, siguiendo su interpretación, son meramente declarativas en la versión universalista ilustrada. Los cristianos se deciden por una fraternidad, aceptan el mensaje de Cristo, y de ahí nutren las acciones de amor al prójimo que este exige.

La concreción de esta fraternidad cristiana se halla en un documento redactado en 2009 ya como Sumo Pontífice: la encíclica Caritas in veritate. Tomando Populorum progressio (1967) como referencia, entiende la cuestión social como cuestión antropológica (Ratzinger, 2009, § 75; Viola, 2009; Schlag, Mercado, 2012) y se sitúa de pleno en la Doctrina Social de la Iglesia, la cual avanza y se desarrolla a partir de fundamentos metafísicos.

El contexto sociocultural y geopolítico de la encíclica es la globalización concebida como interdependencia de hecho entre los seres humanos: ¿cómo conjugar la interdependencia económica, comercial y política con la interdependencia ética de las conciencias?

Una parte de la respuesta se halla en el tercer capítulo, donde se especifica qué papel corresponde a la fraternidad en la actualización o renovación de la DSI. La fraternidad se vincula a la gratuidad, a la "sorprendente experiencia del don" (Ratzinger, 2009, § 34), la cual se contrapone a la concepción de la existencia humana en términos de productividad y utilidad.

"Por su naturaleza, el don supera el mérito, su norma es sobreabundar. Nos precede en nuestra propia alma como signo de la presencia de Dios en nosotros y de sus expectativas para con nosotros" (Ratzinger, 2009, § 34).

El don supone la trascendencia, el hecho de que el hombre no está solo, y que encerrarse en sí de manera egoísta implica el pecado. Un pecado que se manifiesta concretamente en una economía que no se somete a las exigencias éticas. El contexto de una crisis que en 2009 era solo incipiente late en la propuesta de una política que recupere su autonomía frente a la economía, que no se someta a los dictados de esta. Se trata de pasar de una economía autónoma a una política autónoma; de una política que va a rebufo de la economía, a una economía sometida a las leyes y encauzada por la democracia hacia el bien común. 
La caridad es un don recibido por todos que constituye la comunidad, continúa Benedicto XVI. Esta comunidad es universal y puede ser plenamente fraterna, pero solo se logrará si nos apercibimos de que todos hemos sido convocados por la palabra de Dios-Amor. La fraternidad nace de compartir este vínculo gratuito. Y esta gratuidad se contrapone a las exigencias de la economía autonomizada. "El desarrollo económico, social y político necesita, si quiere ser auténticamente humano, dar espacio al principio de gratuidad como expresión de fraternidad." (Ratzinger, 2009, § 34). Así, mientras en el mercado impera la justicia conmutativa que regula las relaciones de dar y recibir, la DSI atribuye mayor importancia a la justicia distributiva y a la justicia social. No se trata de la igualdad aritmética, sino de dar según las necesidades. No hay intercambio, sino regalo. No hay precios, sino generosidad, gratuidad.

"Si el mercado se rige únicamente por el principio de la equivalencia del valor de los bienes que se intercambian, no llega a producir la cohesión social que necesita para su buen funcionamiento. Sin formas internas de solidaridad y de confianza recíproca, el mercado no puede cumplir plenamente su propia función económica." (Ratzinger, 2009, § 34)

La crisis presente se debe a una economía independiente que ha olvidado los vínculos que la anteceden y que no se basa en relaciones de confianza. Si se dan estas relaciones, si se reconoce el vínculo comunitario gratuito, es posible mejorar la economía, hacerla más justa, no solo en términos conmutativos, sino también sociales. De ahí que concluya que es necesario nutrir al mercado de "energías morales".

En el intercambio comercial habitual se presupone un precio que debe ser conocido antes de la transacción y la obligación de actuar recíprocamente una vez se ha cerrado el trato. El intercambio fraterno tiene otras características, pues los implicados se relacionan libremente sin que se trate de precios ni de la obligación de actuar recíprocamente. Es esta "una relación intersubjetiva frágil: quien inicia la relación corre siempre el riesgo de encontrarse frente a un oportunista que se limita a recibir" (Zamagni, 2009a, 76). La lógica del don pertenece al ámbito de las obligaciones morales y no al de los deberes legales, de ahí su fragilidad.

En la DSI, según Benedicto XVI, se reconoce la validez de la economía de mercado como creadora de riqueza, pero hay un esfuerzo por encauzarla en términos sociales. La actividad económica no puede estar alejada de la ética. Recuerda esto el énfasis durante los años 80 y 90 en la "responsabilidad social de la empresa" (Zamagni, 2007). Conviene señalar que en el desarrollo papal de este concepto se aprecia un esfuerzo por evitar las habituales críticas a la RSE, a saber, que se trata de una estrategia de márketing, de una excusa para ocultar deficiencias empresariales, y de una ideología destinada a legitimar un orden económico profundamente injusto. En la versión de Zamagni (y de manera menos explícita en Caritas in veritate), la RSE no solo es una operación de transparencia, sino que se vincula la eficiencia a otros requisitos más propios de entidades sin ánimo de lucro (Zamagni, 2013).

"En las relaciones mercantiles el principio de gratuidad y la lógica del don, como expresiones de fraternidad, pueden y deben tener espacio en la actividad económica ordinaria" (Ratzinger, 2009, § 36) 
La fraternidad se expresa, pues, en la gratuidad y el don: un principio y una lógica que conciben la economía como una forma de sociabilidad. Esta lógica del don se contrapone a la centralidad del contrato propia de la visión económica clásica de los intercambios sociales. El contrato regula el intercambio de bienes, el dar y el recibir, afianza la confianza sobre disposiciones legales. En las relaciones contractuales se salvaguardan los derechos del consumidor, del productor y del comerciante, pero no se alimenta el tejido social. De ahí que, en el orden establecido por esta encíclica, deban ser complementadas por la lógica del don que guía las propuestas propiamente políticas de la encíclica:

“En la época de la globalización, la actividad económica no puede prescindir de la gratuidad, que fomenta y extiende la solidaridad y la responsabilidad por la justicia y el bien común en sus diversas instancias y agentes. Se trata, en definitiva, de una forma concreta y profunda de democracia económica. La solidaridad es en primer lugar que todos se sientan responsables de todos; por tanto, no se la puede dejar solamente en manos del Estado" (Ratzinger, 2009, § 38).

En el ámbito económico, pues, la lógica del don se refleja en la existencia de organizaciones que no están orientadas solo al provecho, que no lo tienen como fin en sí. Organizaciones que no están plenamente reguladas, es decir, que disponen de margen de operación frente al Estado, y que forman parte del tejido social.

Con su Encíclica, Ratzinger plantea la necesidad de revisar la DSI a causa de la globalización. Ya no se trata, como se dijo en Rerum novarum, de la intervención redistributiva del Estado, sino de una colonización ética del mercado que sustituya el "dar para tener" y el "dar por deber" que se corresponden respectivamente al mercado y a la imposición fiscal del Estado. Esta colonización ética se daría en la "apertura progresiva en el contexto mundial a formas de actividad económica caracterizada por ciertos márgenes de gratuidad y comunión" (Ratzinger, 2009, § 39). Quede claro que no se trata aquí de filantropía, un concepto paternalista y no emancipador que no responde a la transformación radical de las relaciones de intercambio propuestas por el Papa (Viola, 2009, 67).

La globalización es expresión de la unidad de la familia humana, pero debe ser corregida y complementada para reducir su capacidad de erosión de las relaciones sociales. Esta erosión se contrarresta enfatizando los vínculos de la familia humana para lograr un desarrollo colaborativo de los pueblos.

Se manifiesta aquí el universalismo inherente al mensaje cristiano entendido como "la inclusión relacional de todas las personas y de todos los pueblos en la única comunidad de la familia humana" (Ratzinger, 2009, § 54). Una fraternidad entre los humanos que no excluye a los no creyentes, sino que incluyéndolos puede acrecentar la colaboración hacia el bien común.

La fraternidad se manifiesta en formas de relación no basadas en el provecho, sino en la gratuidad y el don, instrumentos con los que evitar la tendencia de la economía a autonomizarse. El punto de partida no es el individuo como haz de deseos, sino su vínculo con los otros.

Se observa efectivamente que, si bien se identifican los problemas y se señalan los cambios conceptuales necesarios para solucionarlos, no se indican las medidas concretas. Como 
se sostiene en la misma encíclica, "la Iglesia no tiene soluciones técnicas que ofrecer y no pretende de ninguna manera mezclarse en la política de los Estados" (Ratzinger, 2009, § 9). Dentro de este margen de vaguedad propio de la DSI, más dirigida a los fieles que a los teóricos del Estado, más a los ciudadanos que a los gobernantes, afirma Benedicto XVI que la autoridad política no se debe entender en los términos tradicionales, y que ha adquirido un "significado polivalente" (Ratzinger, 2009, § 41), es decir, la soberanía estatal se ha diluido en la constelación postnacional. La teoría del Estado no puede usar parámetros clásicos. La democracia se debilita en el interior de Estados cuyas fronteras ya no están dibujadas con los claros contornos de antaño. Estas son las rerum novarum a las que Caritas in veritate intenta dar respuesta, para lo cual se apoya en el potencial universalista y no reducido a la escala estatal de la fraternidad cristiana.

A pesar de que no se halla una respuesta definitiva a cómo debe realizarse la fraternidad, Benedicto XVI no abandona plenamente la importancia también institucional de las obligaciones fraternas. Lo hace a propósito del bien común, otro de los pilares de la Doctrina Social de la Iglesia:

“Desear el bien común y esforzarse por él es exigencia de justicia y caridad. Trabajar por el bien común es cuidar, por un lado, y utilizar, por otro, ese conjunto de instituciones que estructuran jurídica, civil, política y culturalmente la vida social, que se configura así como polis, como ciudad. Se ama al prójimo tanto más eficazmente, cuanto más se trabaja por un bien común que responda también a sus necesidades reales. Todo cristiano está llamado a esta caridad, según su vocación y sus posibilidades de incidir en la polis. Esta es la vía institucional - también política, podríamos decir-de la caridad, no menos cualificada e incisiva de lo que pueda ser la caridad que encuentra directamente al prójimo fuera de las mediaciones institucionales de la polis" (Ratzinger, 2009, § 7, mi cursiva).

No se trata, pues, de limitar el compromiso con el bien común de los cristianos a las actividades libres de la sociedad civil, sino de contribuir a las instituciones políticas que centralizan los esfuerzos para paliar las desigualdades sociales. Por tanto, a la lógica eminentemente liberal propia del principio de subsidiariedad, Benedicto XVI añade la institucionalización de las obligaciones fraternas en pro del bien común. Se dibuja, pues, un acercamiento mixto a la fraternidad, según el cual hay una labor colaborativa entre la sociedad y el Estado, reduciendo la acción de este a "lo que la sociedad civil no puede alcanzar por sí misma" (como reza la definición del diccionario de la RAE de "principio de subsidiariedad"), pero reconociendo al mismo tiempo que hay espacios que no pueden ser cubiertos por la sociedad civil y que por tanto es obligación del Estado ocuparse de ellos.

\section{El concepto de subsidiariedad en la Doctrina Social de la Iglesia}

El hecho de que no se ofrezcan modelos claros y precisos sobre cómo debería aplicarse a nivel institucional la fraternidad para superar las injusticias del mundo globalizado obedece a la importancia del principio de subsidiariedad en la Doctrina Social de la Iglesia, tal y como se encuentra ya en Centessimus annus (1991) de Juan Pablo II. Con la subsidiariedad, la 
DSI se alinea en la lógica liberal de los cuerpos intermedios entre el Estado y el individuo. Se afianza así una interpretación de la fraternidad que la encomienda a la libre interacción ciudadana, alejándola de una institucionalización plena. Correspondería, pues, a los ciudadanos la actividad fraterna o caritativa, que no debe encontrar obstáculos institucionales. La fraternidad no puede ser obligada, sino voluntaria. El Estado no puede ni debe hacerse cargo de todas las competencias referidas a la justicia social y delega en la sociedad civil esta tarea. El Estado del bienestar cede paso a la libre solidaridad entre los ciudadanos.

En Caritas in veritate se dice específicamente sobre el principio de subsidiariedad:

"La subsidiariedad es ante todo una ayuda a la persona, a través de la autonomía de los cuerpos intermedios. Dicha ayuda se ofrece cuando la persona y los sujetos sociales no son capaces de valerse por sí mismos, implicando siempre una finalidad emancipadora, porque favorece la libertad y la participación a la hora de asumir responsabilidades. La subsidiariedad respeta la dignidad de la persona, en la que ve un sujeto siempre capaz de dar algo a los otros. La subsidiariedad, al reconocer que la reciprocidad forma parte de la constitución íntima del ser humano, es el antídoto más eficaz contra cualquier forma de asistencialismo paternalista." (Ratzinger, 2009, § 57)

El principio de subsidiariedad, pues, garantiza un espacio social libre de interferencias para que los ciudadanos se ayuden mutuamente. Benedicto XVI contrapone la subsidiariedad al Estado en su versión asistencialista, adjetivo con el que quiere denotar que las ayudas estatales a las personas en situación de precariedad no sirven para la emancipación de estas, sino que las convierten en clientes del Estado y no atienden sus necesidades profundas ni su dignidad.

La línea de interpretación de este principio la marcó ya como Prefecto para la Congregación de la Doctrina de la Fe con el texto Libertad cristiana y liberación:

"En virtud del principio de solidaridad, el hombre debe contribuir con sus semejantes al bien común de la sociedad, a todos los niveles. Con ello, la doctrina social de la Iglesia se opone a todas las formas de individualismo social o político. En virtud del principio de subsidiariedad, ni el Estado ni sociedad alguna deberán jamás substituir la iniciativa y la responsabilidad de las personas y de los grupos sociales intermedios en los niveles en los que éstos pueden actuar, ni destruir el espacio necesario para su libertad. De este modo, la doctrina social de la Iglesia se opone a todas las formas de colectivismo." (Congregación, 1986, § 73).

Ni colectivismo, ni individualismo, sino una vía intermedia basada en la concepción relacional de lo humano (principio de solidaridad) la cual empuja a una cooperación que no puede ser sustituida por la actividad de las instituciones. Las leyes inscritas en el corazón de los hombres, leyes naturales, son pues superiores a las leyes creadas por los hombres. Estas actitudes de ayuda gratuita refuerzan el tejido social, impulsando a la comunidad hacia "formas más elevadas de sociabilidad" (Pontificio, 2004, § 185). Este principio "protege a las personas de los abusos de las instancias sociales superiores e insta a estas últimas a ayudar a los particulares y a los cuerpos intermedios a desarrollar sus tareas. Este princi- 
pio se impone porque toda persona, familia y cuerpo intermedio tiene algo de original que ofrecer a la comunidad". El Estado y el aparato público amenazan con tener una presencia “injustificada y excesiva” (Pontificio, 2004, § 187). La intervención pública debe darse solo en circunstancias excepcionales y hasta que estas hayan sido superadas, adoptando como criterio el "bien común correctamente entendido" (Pontificio, 2004, § 188).

La DSI se adhiere, con su énfasis en el principio de subsidiariedad, a la concepción liberal de la sociedad, según la cual el Estado debe dejar margen de acción a las iniciativas ciudadanas. Los motivos para este trabajo cooperativo entre sociedad civil e instituciones del Estado son tanto de eficacia como de principio: el Estado no puede llegar a todas partes y debe respetar la libre iniciativa de las personas.

Este concepto de subsidiariedad encuentra un reflejo en la legislación, como lo demuestra la modificación en 2001 del artículo 118.4 de la Constitución italiana: "El Estado, las Regiones, las Ciudades metropolitanas, las Provincias y municipios favorecen la iniciativa autónoma de los ciudadanos, individualmente o asociados, para el desarrollo de las actividades de interés general, sobre la base del principio de subsidiariedad".

Los ciudadanos deben poder determinar libremente cuáles son las prioridades para lograr el bien común. El Estado debe solo apoyar, coordinar o gestionar las necesidades identificadas por los propios ciudadanos en su interacción fraterna. Esa es su función subsidiaria: no intervenir o intervenir solo en los términos establecidos por la sociedad civil. La lógica del concepto es la liberal y es la adoptada por las confesiones religiosas cuando se trata de defender un espacio de influencia social, o sea, un pleno uso de la libertad religiosa de pensamiento y de acción. Como señala Staiano, en la reforma de 2001 actúa una doble matriz, católica y liberal, centrada en la libertad de acción y el sostén estatal para las asociaciones que fortalecen los vínculos entre las personas y, con ello, la sociedad civil (Staiano, 2006; Cassese, 1995). La Iglesia postconciliar pasa a formar parte de la sociedad civil, reconoce el pluralismo de la sociedad y está dispuesta a abandonar los "privilegios dados por el poder civil", pero reclama su derecho "en todo momento y en todas partes a predicar la fe con auténtica libertad, enseñar su doctrina social, ejercer su misión entre los hombres sin traba alguna y dar su juicio moral, incluso sobre materias referentes al orden político, cuando lo exijan los derechos fundamentales de la persona o la salvación de las almas, utilizando todos y solo aquellos medios que sean conformes al Evangelio y al bien de todos según la diversidad de tiempos y de situaciones" (Gaudium et spes, $\$ 76$ ).

Como explica recientemente Finkielkraut, los creyentes se defienden en términos de libertad religiosa, utilizando aquello que la religión monoteísta combate cuando está aliada con el poder político, la libertad (Finkielkraut, 2014). La actitud liberal se basa en el reconocimiento de que "la comunidad política y la Iglesia son independientes y autónomas, cada una en su propio terreno" (Gaudium et spes, § 76) ${ }^{2}$. El énfasis en la subsidiariedad ofrece una justificación para que el Estado reduzca su ámbito de acción, pues debe dejar el campo libre para que la sociedad, los individuos y los colectivos, se organicen de manera voluntaria para dotarse de los bienes y de los servicios que creen más deseables. El principio de subsidiariedad acentúa la vertiente no institucional de la fraternidad: las acciones fraternas no

2 Esta afirmación debería ser contrastada con lo enunciado por el propio Rawls en su tesis de 1942 (Rawls, 2009; Habermas, 2010). 
pueden ser el producto de una coacción legal, sino que necesitan de una motivación personal que solo puede surgir del compromiso libre y organizado de colectivos que se despliegan en la sociedad sin hallar obstáculos institucionales. En la salvaguarda de la justicia social, el Estado debe reconocer este derecho de libre asociación, pues él solo no puede cumplir con sus propias expectativas.

\section{Conclusiones}

De la lectura de la DSI y la teología ratzingeriana se siguen una serie de desafíos para la construcción de un concepto normativo-político de fraternidad.

El principio de subsidiariedad nos ilustra sobre la dialéctica entre sociedad civil e instituciones jurídico-políticas: las instituciones deben beber de los impulsos procedentes de la sociedad y deben también corregir las desviaciones que se den en ella. Dicho en otros términos, la fraternidad social puede alimentar o inspirar el comportamiento de las instituciones. ${ }^{3}$

La Iglesia no tiene como objetivo señalar cuáles deberían ser las instituciones ni las políticas concretas que deberían realizar la fraternidad o que deberían guiar sus decisiones. La fraternidad cristiana no tiene, pues, un vínculo directo con la política institucional, es, como lo pone Hunyadi, "pre-política", también por tanto pre-jurídica (Rossi, 2013, 808).

En la DSI, la fraternidad no es el espacio de las instituciones políticas, sino el humus social de estas instituciones. Corresponde a la sociedad civil ejercer las obligaciones fraternas. En los cuerpos intermedios se aprende la virtud que se extiende hacia toda la familia humana. Esta confianza en la sociedad civil contrasta con la fraternidad jacobina que ve en ella el germen de la desunión a manos de las facciones sociales (Giubboni, 2012).

Como muestra Mark Hunyadi, la fraternidad ha tenido a lo largo de la historia un valor más "retórico y declamatorio que legal o institucional" (Hunyadi, 2006, 154). Se trata, además, en el caso de la fraternidad cristiana de un concepto performativo, una invocación, una exhortación a la acción de los individuos y de la sociedad civil, con un potencial transformador en la medida en que el mensaje universal trasciende las fronteras estatales y se adecúa por tanto a la coyuntura globalizada. ${ }^{4}$

Por otra parte, la reconstrucción de la fraternidad por el joven Ratzinger incluye su doble cara exclusiva/inclusiva. Sin una Bruderschaft previa, una hermandad, no se cuenta con la fuerza motivacional para las acciones fraternas. Este vínculo solo se puede aplicar a las instituciones de forma metafórica. La fraternidad no puede ser institucionalizada en la medida en que es un sentimiento que se crea entre los individuos, que puede ser cultivado, y para el cual hay también buenas razones interesadas y desinteresadas. Manteniendo esta doble naturaleza de lo fraterno, Ratzinger critica por excesivamente abstractas las pretensiones universalistas de la fraternidad ilustrada subrayando la necesidad de que haya un elemento motivacional, el cual es el resultado del aprendizaje de la fraternidad en las comunidades de fieles.

3 Así también cabe entender lo dicho por Jules Dufaure en el discurso de presentación de la constitución de 1848 ante la Asamblea nacional francesa a propósito de la inclusión del derecho de asistencia fraterna en el apartado VIII de su preámbulo: "por primera vez el precepto cristiano que renovó la cara del mundo hace 1800 años pasa a ser la base de todo un código administrativo" (citado en Le Goff, 2013).

4 Rasgos de la fraternidad que se hallan tanto en el análisis de Hunyadi como en la DSI. 
Hoy la fraternidad se piensa en contextos que trascienden las fronteras nacionales. Los desarrollos católicos de la fraternidad prestan atención a la justicia local, a las políticas que los países pueden realizar para mejorar la pobreza y la paz en los territorios nacionales, pero el impulso fraterno va más allá de las fronteras en la medida en que vincula a los que están separados, a los que no se conocen, a los que no comparten con nosotros nada más que la misma humanidad. La crítica al institucionalismo en este caso se debe no solo al hecho de que la fraternidad es algo demasiado importante para dejarlo exclusivamente en manos del Estado, sino también al hecho de que el problema que requiere solución es global y no local.

Este universalismo desacomplejado del catolicismo no puede ser recogido tal cual por el pensamiento postmetafísico. Sin embargo, hoy, cuando no hay justificación ética para limitar la solidaridad a los territorios nacionales, estatales o siquiera continentales, el gesto universalista, católico, puede contribuir, con sus justificaciones metafísicas convenientemente traducidas, al compromiso internacional de la responsabilidad de proteger de atrocidades masivas y violaciones de derechos humanos.

La performatividad de la fraternidad se manifiesta económicamente en la modificación radical de los intercambios ciudadanos. Las personas no solo deben reflexionar sobre sus estilos de consumo, sino que debe abandonarse el "eficientismo": la eficiencia como fin y no como medio supeditado a fines que no deben ser exclusivamente económicos sino integradores de la vida social. En este sentido, la fraternidad no se traduce en acuerdos institucionales, en políticas económicas, sino en una economía reconducida hacia la sociedad. El mercado es "un momento importante de la esfera pública -esfera que es bastante más vasta que la estatal- el cual, si es concebido y vivido como lugar abierto a los principios de la reciprocidad y del don, puede construir la "ciudad"” (Zamagni, 2009a, s80). Esta ciudad mencionada de manera enfática se basa en un vínculo gratuito. No se trata, pues, de dejar que el mercado colonice la sociedad civil, sino de que la sociedad civil entre en el mercado para modificar sus reglas, para lograr lo que Zamagni llama un nuevo paradigma científico, el "paradigma relacional" vinculado a la tradición de la economía civil de los humanistas italianos y que se halla presente también en la obra de Adam Smith (Zamagni, 2008). ${ }^{5}$

Los críticos del liberalismo, y por tanto también del principio de subsidiariedad tal y como lo interpreta la DSI, sostienen que una fraternidad limitada a las acciones voluntarias de la sociedad civil es mera "caridad, beneficencia, compasión", y presupone y consolida "la subalternidad de quien es objeto de estas acciones" (Rodotà, 2014, 25). En este contexto, resulta especialmente ilustrativa la recuperación rawlsiana de Munoz-Dardé, que le lleva a proponer una fraternidad contractual que no apela a derechos naturales previos al contrato, sino al reconocimiento recíproco de los intereses de cada cual y la voluntad de llegar a un acuerdo justo sobre la cooperación social. Este contrato socialdemócrata garantiza que "los intereses singulares de cada persona son objeto de una atención común imparcial" (MunozDardé, 2001, 659). La perspectiva contractualista defiende la importancia de considerar a los individuos como creadores de los términos de su coexistencia, lo cual los sitúa en una situación autointeresada que implica necesariamente la prioridad de la libertad sobre la igualdad, siguiendo la lógica de John Rawls en A Theory of Justice.

5 El proyecto de Zamagni se enmarca en una crítica a los economistas técnicos y analíticos, a los cuales contrapone una economía comprometida con una visión antropológica específica del ser humano. 
Hay una disparidad sobre el modo de interpretar la imparcialidad. Para la teoría liberal la justicia es imparcial cuando no hace diferencias ni muestra sesgos emocionales o ideológicos. Esta neutralidad aspira a ser justa en sus principios, pero también en sus efectos. La imparcialidad cristiana tampoco hace diferencias entre los seres humanos tomados abstractamente. Sin embargo, se entiende de manera primordial como una práctica referida directamente a un alguien concreto a quien se sirve. Esta práctica implica no tanto la racionalidad o el cálculo de los mejores efectos por parte del agente, sino la totalidad de su persona, sus afectos, sus emociones y sus compromisos religiosos y sociales.

La fraternidad contractual presupone una decisión antropológica, en concreto, la que se halla implícita en la teoría liberal que abandona el paradigma aristotélico de la naturaleza política del hombre y adopta la perspectiva del individuo que se relaciona cooperativa y conflictivamente con sus congéneres. La toma de partido por la concepción individualista y conflictual de la naturaleza humana dificulta la aplicación del concepto de fraternidad, el cual se refiere precisamente a una institución natural, en la medida en que los seres humanos han encontrado un modo de sobrevivir consistente en juntarse en familias y fundar ciudades en donde los hombres pueden alcanzar la excelencia, como sostenía Aristóteles. El carácter previo del vínculo fraterno, a diferencia del carácter posterior del contrato instaurador de la fraternidad, ofrece una guía normativa para la acción social. A saber, nos debemos algo unos a otros porque somos hermanos. La fraternidad contractual en cambio dice que somos hermanos porque nos debemos algo unos a otros. Un abismo ontológico separa ambas afirmaciones.

El contractualismo liberal concibe las instituciones como filtros que deben garantizar que los deberes de fraternidad no sean excesivos, es decir, no atenten contra las libertades individuales. De modo que se trata de calcular la justa distancia que debe darse entre un individuo y otro. Nunca demasiado lejos como para impedir que nos identifiquemos con el prójimo, pero tampoco demasiado cerca, dado que hay que proteger el coto vedado del individuo. Se da una lógica agonística entre libertad e igualdad concebidas como instancias difícilmente reconciliables que redunda en una "fraternidad conflictual" (Massa Pinto, 2011), una norma prescriptiva que impone a los hombres que se traten como si fueran hermanos justamente porque no lo son. Dada una antropología que acentúa el conflicto, la fraternidad se debe traducir en una imposición del deber de tomar en consideración las demandas de los otros como requisito para una convivencia pacífica.

La fraternidad halla un encaje más natural en las propuestas de justicia que parten de una naturaleza humana relacional, pues la motivación se halla ya en el fundamento antropológico. Se entiende aquí la fraternidad como un sentimiento o una metáfora que exhorta o mueve a una acción futura. No es un principio en nombre del cual se reclamen derechos, sino un modelo que nos invita a la acción.

Mientras que la fraternidad católica confía en la sociedad civil y sostiene que el Estado debe asistir a esta, la fraternidad conflictual y contractual pone el énfasis en las instituciones estatales que deben corregir las desigualdades sociales aplicando el principio de fraternidad. El institucionalismo cambia las confianzas metafísicas por la certeza de que existe un poder coercitivo que puede garantizar el cumplimiento de la ley. ${ }^{6}$

6 El institucionalismo trascendental, como lo llama Amartya Sen, "se dedica de manera primaria a hacer justas las instituciones, por lo cual no se ocupa realmente de las sociedades reales" (Sen, 2010, 38). 
Concluyo sosteniendo que las teorías de la justicia que pretenden recoger el legado de la fraternidad dejando de lado su trasfondo metafísico y sustituyéndolo por una antropología individualista y conflictual, están condenadas a un enorme trabajo de justificación. Una fraternidad basada en un contrato resulta un buen experimento mental para ilustrar las dificultades de la cooperación social, pero supone un uso forzado del término, dado que no aprovecha su enraizamiento en una práctica comunitaria que garantiza la motivación para la acción y ejercita a los individuos en sus deberes fraternos con el prójimo.

Así las cosas, la perspectiva postsecular parece adecuada, pues no descarta que del acervo religioso surjan energías para construir un consenso ético que contribuya a sostener a las democracias liberales del siglo XXI en su lucha contra la discriminación, la xenofobia o la destrucción del planeta. La fraternidad cristiana, articulada democráticamente, puede indicar el límite excesivo hacia el que deben tender las ciudades y la solidaridad entre ellas.

\section{Agradecimientos}

Este trabajo se enmarca en el Proyecto de Investigación "Fraternidad, justicia y democracia" (FFI 2012-33370). Agradezco las amables ayudas y recomendaciones bibliográficas de Umberto Ronga de la Università Federico II di Napoli.

\section{Bibliografía}

Cassese, Sabino (1995): “L'aquila e le mosche. Principio di sussidiarietà e diritti amministrativi nell'area europea", Foro It, V, pp. 373-378.

Congregación para la Doctrina de la Fe. (1986): Libertatis conscientia. Instrucción sobre libertad cristiana y liberación. [Fecha de consulta: 27 de abril de 2018]. Disponible en: http://www.vatican.va/roman_curia/congregations/cfaith/documents/rc_con_cfaith_ doc_19860322_freedom-liberation_sp.html.

Finkielkraut, Alain (2014): La identidad desdichada, Madrid, Alianza.

Giubboni, Stefano (2012): "Solidarietà", Politica del diritto, XLIII, 4, pp. 525-553.

Grillo, Girolamo (2010): Sommario della dottrina sociale della Chiesa, Génova-Milán, Marietti.

Habermas, Jürgen (2010): “Das 'gute Leben' eine 'abscheuliche Phrase'. Welche Bedeutung hat die religiöse Ethik des jungen Rawls für dessen Politische Theorie?”, Deutsche Zeitschrift für Philosophie, vol. 58, pp. 797-809.

Hunyadi, Mark (2006): “Dangereuse fraternité?”, en: O. Inkova (ed.), Justice, Liberté, Egalité, Fraternité: Sur quelques valeurs fondamentales de la démocratie européene (pp. 153-172), Ginebra, Eyropa - Institut européen de l'Université de Genève.

Le Goff, Jaques (2013): "Fraternità: un diritto che non esiste”, Aggiornamenti Sociali, 3/64, pp. 190-199.

Massa Pinto, Ilenia (2011): Costituzione e fraternità. Una teoria della fraternità conflittuale: "come se" fossimo fratelli, Nápoles, Jovene.

Munoz-Dardé, Veronique (2001): "Fraternidad”, en: M. Canto-Sperber (ed.), Diccionario de ética y de filosofía moral, México, FCE, pp. 655-659.

Nozick, Robert (1974): Anarchy, State, and Utopia. Nueva York: Basic. 
Pizzolato, Filippo (2012a): "Fraternità (principio di)", en: Digesto delle discipline pubblicistiche, V aggiornamento, Torino, UTET, pp. 378-402.

Pizzolato, Filippo (2012b): Il principio costituzionale di fraternità. Itinerario di ricerca a partire dalla Costituzione italiana, Roma, Città Nuova.

Pontificio Consejo "Doctrina y Paz". (2004): Compendio de la Doctrina Social de la Iglesia. [Fecha de consulta: 27 de abril de 2018]. Disponible en: http://www.vatican.va/ roman_curia/pontifical_councils/justpeace/documents/rc_pc_justpeace_doc_20060526_ compendio-dott-soc_sp.html.

Ratzinger, Joseph (2006): Die christliche Brüderlichkeit, Múnich, Kösel. (trad.: (2004): La fraternidad de los cristianos, Salamanca, Sígueme).

Ratzinger, Joseph / Benedicto XVI, (2009), Caritas in veritate. [Fecha de consulta: 27 de abril de 2018]. Disponible en: http://www.vatican.va/holy_father/benedict_xvi/encyclicals/documents/hf_ben-xvi_enc_20090629_caritas-in-veritate_sp.html

Rawls, John (1971): A Theory of Justice, Oxford, Oxford University Press.

Rawls, John (2009): A Brief Inquiry into the Meaning of Sin \& Faith, Cambridge (Mass.), Harvard University Press.

Rodotà, Stefano (2014): Solidarietà. Un'utopia necessaria, Roma-Bari, Laterza.

Rossi, Stefano (2013): "Fraternità e mutualismo: forme nuove di un legame antico", Diritto Pubblico 3, pp. 807-861.

Sandel, Michael (2000): El liberalismo y los límites de la justicia, Barcelona, Gedisa.

Schlag, Martin y Mercado, Juan Andrés (2012): Free Markets and the Culture of Common Good, Dordrecht, Springer.

Sen, Amartya (2010): La idea de justicia, Madrid, Taurus.

Staiano, Sandro (2006): "La sussidiarietà orizzontale: profili teorici”, Federalismi.it, vol. 5, pp. 1-29.

Taylor, Charles (1994): La ética de la autenticidad, Paidós, Barcelona.

Velasquez, Manuel (1986): “Gaudium et Spes' and the Development of Catholic SocialEconomic Teaching”, en: J. A. Dwyer (ed.), Questions of Special Urgency: The Church in the Modern World Two Decades After Vatican II, Washington DC, Georgetown University Press, pp. 177-178.

Viola, Francesco (2009): "Non c’è carità senza giustizia, non c’è giustizia senza carità", en: Carità Globale. Commento alla 'Caritas in veritate', Ciudad del Vaticano, Libreria Editrice Vaticana, pp. 63-77.

Zamagni, Stefano (2007): L'economia del bene comune, Roma, Città Nuova.

Zamagni, Stefano (2008): "Reciprocity, Civil Economy, Common Good", en: M. Archer, P. Donati (eds.), Pursuing the Common Good. Ciudad del Vaticano, The Pontifical Academy of Social Sciences, Ciudad del Vaticano, pp. 467-502.

Zamagni, Stefano (2009a): "Fraternità, dono, reciprocità nella Caritas in veritate, en: Amore $e$ verità. Commento e guida alla lettura dell'Enciclica Caritas in veritate", Milán: Paoline, pp. 71-103. (Trad: (2009), "Fraternidad, don y reciprocidad en la Caritas in veritate”, Revista Cultura Económica, XXVII, 75 / 76, pp. 11-29).

Zamagni, Stefano (2009b): Avarizia. La passione dell'avere, Bologna, Il Mulino.

Zamagni, Stefano (2013): Impresa responsabile e mercato civile, Bologna, Il Mulino. 
